\title{
An Analysis of Cultural Differences Effect on Tourist Behaviors in Macau
}

\author{
Xi Li ${ }^{1}$, Anwei Yin ${ }^{1}, \&$ Jian Ming Luo ${ }^{1}$ \\ ${ }^{1}$ Faculty of International Tourism and Management, City University of Macau, Macau \\ Correspondence: Anwei Yin c/o Xi Li, Faculty of International Tourism and Management, City University of \\ Macau, Avenida Xian Xing Hai, Ed.Golden Dragon Centre, 4º andar, Macau. Tel: 1-853-8590-2241. E-mail: \\ ruguokey_1774@qq.com
}

Received: June 26, 2015 Accepted: August 10, 2015 Online Published: September 29, 2015

doi:10.5539/ijms.v7n5p25 URL: http://dx.doi.org/10.5539/ijms.v7n5p25

This study is supported by Macau Fundation.

\begin{abstract}
Gaming industry is the pillar of Macao's economy. The content of the gaming industry has become more extended and dynamic due to Mainland China policies and strategies of Macao government in tourism industry. As a leisure tourism destination with the gaming industry in Asia, Macao has become a popular tourist destination. This study tries to explore the impacts of cultural differences on gaming behaviors and reports on the observations of a convenience sample of 196 tourists in Chinese and non-Chinese. The results show that the nationality variable had a significant effect on the gambling, entertainment, shopping, and Food and beverage behaviors. The researchers provide some suggestions to government officers and gaming industry operators.
\end{abstract}

Keywords: cultural differences, gaming, gaming behaviors, Macao

\section{Introduction}

Macao is the Special Administrative Region in People's Republic of China and is the only region that has Mainland China government approval for commercial gambling. With more than 150 years of experience in the gaming industry, the gaming industry has become the backbone of Macao's economy. Tens of millions of tourists come to Macao annually to gamble, and gaming industry is driving other related industries. According to Macao's Statistics and Census Service (2015), gaming industry receipts have been the dominant part of the Macao GDP for decades. In 2013, the receipt of gambling and related services revenue were MOP 362,750 million. It accounted for $87.73 \%$ of the Macao GDP, and the average rate from 2009 to 2014 was $83.97 \%$. The tax of gambling industry income for Macao government made up $86.41 \%$ of the total income of government tax, with the average rate of $78.5 \%$. The proportion chart from 2009 to 2014 is shown in Figure 1 below. From 2009 to 2013 , the rate of increase of receipts from gambling and related services are $30.5 \%, 57 \%, 42 \%, 13.5 \%$, and $18.4 \%$. However, in 2014 , for the first time a reduction happened and the rate was negative $2.85 \%$. In order to keep long-term and stable development, Macao government has had to change their strategy as a 'gaming city' to a 'leisure tourism city'. The term 'gaming' has been described as the casino gambling industry relatively (See Figure 1).

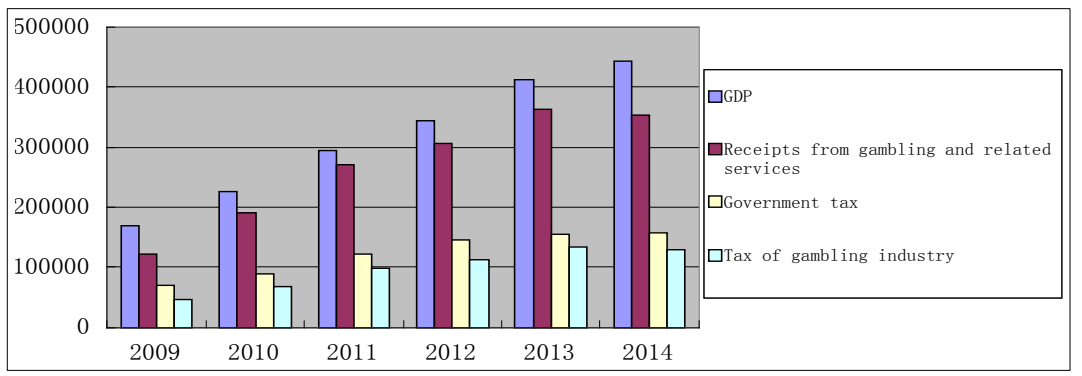

Figure 1. The proportion of gambling receipt and tax on GDP and government tax

Unit: Million MOP. (Source: Macao's Statistics and Census Service, 2010-2015) 
By analyzing the tourist markets in Macao, we found that the Asian tourist market is the largest source of Macao tourism, it occupied nearly $97 \%$ of the total market share in 2009 to 2014 . Mainland China, the number-one source of tourism to Macao, currently represents $63.5 \%$ of the tourist market. While the Hong Kong market, with the second largest source, represents $23.1 \%$ of market share. The Taiwan market is the third largest single source, representing 3.4\% market share. Followed by Republic of Korea, Japan, Malaysia, Thailand and Singapore. According to the above, a large number of inbound tourists with different cultural backgrounds enrich the cultures. In the meantime, to be able to provide the kinds of products each cultural group preferred is emergent. There has been very few study on the relationship between cultural difference and gaming behaviors to help designing gaming products. Understanding the tourists in terms of their cultural differences and gaming behaviors can provide specific and innovative information to destination marketers and gaming industry operators.

\section{Literature Review}

\subsection{Cultural difference}

Culture refers to a character which is stable and regnant to a society shared by most of its individuals and stay the same over long periods of time (Reisinger \& Turner, 2002a; Reisinger \& Turner, 2002b). Differences among cultures were increased by the cultural dimensions of which national cultures are various. Main cultural differences can be identified in cultural values; social categories, and nonverbal behaviors (Reisinger \& Turner, 1997; Reisinger \& Turner, 2002a); communication, service, expectation, western and eastern culture. The cultural difference may induce cultural conflicts. If the cultural differences are large, the cultural distance will separate people and cause cultural conflicts between tourists and the host population (Sutton, 1967; Wei, Crompton, \& Reid, 1989; Reisinger \& Turner, 2002a). The main source of these cultural conflicts are: (1) cultural ethnocentrism, (2) language and interpretation during communication process, (3) differences in lifestyle and customs such as accommodation and food, and (4) lack of understanding, poor quality of service and appreciation of international service standards and visitors' expectations (Wei et al., 1989; Reisinger \& Turner, 2002a).

\subsubsection{The Measurements of Cultural Differences}

Previous studies in the study of culture differences have widely adopted nationality as the basic classification. Pearce and Butler (1993) argued that national boundaries circumscribing should employ alternative approaches such as personality, lifestyles, tourist-roles, social-class for analysis. Pizam and Sussmann (1995) got a conclusion that the nationalities perceived differences resulted from cultural influences and not geographical factors or linguistic (communication) difficulties. Latter, Pizam and Jeong (1996) put forward that perceived nationality differences where residents or tourist entrepreneurs tend to hold specific stereotypes of tourists based on their nationalities, regardless of their country of birth, ethnic background and country of origin. Some researchers considered that different ethnic minority and cultural groups are affected unequally by issues related to gambling. Therefore, they conducted the researches with classification separately and found that some ethnic minority may be easier to fall into problem gambling (Ellenbogen, Gupta, \& Derevensky, 2007). Some researcher also found that compared with western people, Chinese are more active in gambling (Raylu \& Oei, 2004; Oei, Lin, \& Raylu, 2008). Otherwise, there is an immanent limitation, that is called self-report, existing in a series of scaled items which involved the cross-cultural nature. It is recognized that response collected from different cultural groups may not mirror meaningful difference in attitude or response process (Schwarz, 2003; Tsang \& Ap, 2007).

\subsection{Gaming Behavior}

In this article, because of the lack of academic definition of the term 'gaming', we define gaming as a series activities what included gambling, accommodation, shopping, and entertainment in the casino gaming industry. For understanding tourist behaviors, scholars have made use of concepts, models, and theories from disciplines such as marketing, anthropology, sociology, psychology, among others. For example, some apply models for pedestrian behavior such as model with a network of nodes and links for study of route choice behavior (Borgers \& Timmermans, 2005; Kemperman, Borgers, \& Timmermans, 2009). Some researchers put forward that, using means-end chain theory which developed in marketing to better understand personal values as the basis of tourist behaviors (Mclntosh \& Thyne, 2005; McDonald, Thyne, \& McMorland, 2008).

\subsubsection{The Measurement of Gaming Behaviors}

In these studies, researchers mainly used observation by tour guides or employees in casinos to conclude tourist behaviors and player behaviors based on national differences. For example, Pizam and Sussmann (1995) found 
20 behavioral characteristics which were perceived by tour guides. They divided the items in five factors: Social interaction, commercial transactions, activities preferences, bargaining, and knowledge of destination. Soon afterwards, Pizam and Jeong (1996) made use of these items to test the cultural differences among Japanese, American and Korean. Kim, Prideaux and Kim (2002) concluded 28 items of cultural differences among Japanese, Korean resident abroad, Chines (Mainland Chinese, Taiwanese, Hong Kong Chinese), Westerners (US citizens and Europeans) perceived by employees in casinos. Where after, Wan, Kim, and Elliot (2013) divided the 28 items into seven factors and utilized them for analyzing behavioral differences in gaming patterns among Chinese subcultures. Gamblers' behaviors are often analyzed by their frequency of gambling, frequency of visits to particular casinos, the time and money spent gambling at one visit and the game played most often, gambling experience, and gamblers' demographic characteristics (Wan, 2012). Some of the researchers divided shopping behaviors into the approach and avoidance behaviors for environmental study (Mehrabian \& Russell, 1974; Yüksel, 2007).

\section{Methodology}

We developed a twelve-item scale to conclude the typical tourist behaviors during gaming in Macao. We referenced the questions of a questionnaire used by Las-Vegas government and combined the question form to set up our questions. To develop the pilot test questionnaire, we administered a structured questionnaire with the twelve-item to four professors who had worked for more than five years in the gaming industry, ensuring there have sufficient experience in studying the gaming field and have adequate experience in gaming behaviors. Their response to the item scales were consistent, indicating that all twelve-item behavioral items set up appropriately. To further verify the items, we conducted a three-people group whom three are students majoring non-gaming subjects to answer the questionnaire to make sure that each of the questions can be answered without sharing one meaning and can be understood easily. According to the reaction and feedback in place, all three respondents indicating that twelve-item behavioral items were appropriated.

Next, a pilot test with a sample of tourist who are waiting at the ferry terminal lobby was conducted. As recommended by Hinkin (1998), we used 5-point Likert-type scales anchored by strongly disagree (1) and strongly agree (5), with a moderate point at (3). To ensure the accuracy, we asked the tourists who will stay over in Macao for 24 hours and are 21 years old above. Although errors might occur during the recall process, recognized as a study limitation, behaviors are the subject of interest in this study (See Table 1).

Table 1. Gaming tourist behaviors of Chinese and non-Chinese

\begin{tabular}{llll}
\hline Items & Behaviors & Chinese tourist (M) & non-Chinese tourist (M) \\
\hline Item 1 & I tend to gamble to earn money. & 2.00 & 1.75 \\
Item 2 & I tend to gamble. & 2.06 & 1.96 \\
Item 3 & I tend to take time when betting. & 2.65 & 2.14 \\
Item 4 & I tend to gamble in two or more casinos. & 2.91 & 2.02 \\
Item 5 & I tend to play table games. & 2.66 & 1.97 \\
Item 6 & I tend to watch different kinds of shows in Macao. & 3.29 & 2.96 \\
Item 7 & I tend to watch ornamental shows in Macao. & 3.24 & 2.67 \\
Item 8 & I tend to watch the show where I need to pay. & 3.20 & 2.72 \\
Item 9 & I tend to shop in casino outlets. & 2.94 & 2.31 \\
Item 10 & I tend to buy luxury goods. & 2.49 & 2.30 \\
Item 11 & I tend to have meals in casino. & 2.94 & 2.40 \\
Item 12 & I tend to have meals in luxury restaurants. & 2.69 & 2.59 \\
\hline
\end{tabular}

Lastly, a statistical testing of scale to check the validity and reliability of the scales. Exploratory factor analysis resulted in three factors with eigen-values greater than 1 (Kaiser's criterion), all factor loading are all above the standard criterion level of .45 , they are between .572 to .858 , and 64.18 percent of the variance explained. Cronbach's alpha measures of reliability to ensure internal consistency among items in a factor are provided in the 'Result' section (see Table 2) that follows.

\subsection{Data Collection and Analysis}

Once the final questionnaire was determined, it was administered in May 2015 through face-to-face interview with tourists at the airport and ferry terminal who stayed in Macao for over 24 hours and were 21 years old above. To encourage survey completion, The researchers fit the questions on one-sided page to help tourists read quickly and respond with ease. Through the City University of Macao, ten master students in gaming or 
hospitality management were recruited to carry out filed interviews. Five of the students are English speaking people, the rest students could speak Mandarin and Cantonese well. They were familiar with the casino setting through their working experience and casino visits. To ensure data reliability, two researchers who had rich experience in doing surveys were invited and they gave a training for rehearsal.

The researcher divided the interviewers in two groups, one of the group invited Chinese speaking tourists only, the other one focus on non-Chinese speaking tourists. The interviewers read the questionnaire to participants and recorded their answers, in a process that took about 5 minutes to complete. A total of 250 qualified tourists agreed to be interviewed, 54 were discarded due to missing values, 196 completed questionnaires are valid and usable for the analysis.

\subsection{Profiles of Respondents Sample}

The sample comprised the following nationalities: Chinese (45.4\%), non-Chinese (54.6). About 53.6 percent of the participants were male, 33.2 percent were aged between twenty-one and thirty, 29.1 percent were thirty-one to forty, and 17.9 percent were forty-one to fifty. In terms of education, $21.9 \%$ chosen some college (no bachelor's degree), $29.1 \%$ chose graduated college, and $24.0 \%$ chose master or higher. For income, $50 \%$ respondents earned below 20,000USD while $19.9 \%$ earned 58,001 or more.

\section{Finding}

\subsection{Exploratory Factor Analysis Results}

Factor analysis of the twelve items revealed three underlying factors where eigen-values greater than 1.0 (Table 2). Screen plot tests confirmed those eigen-values for the three factors. Based on the existing statistical example (Wan et al., 2013), we chose both orthogonal and oblique rotation techniques. The results of the oblique rotation were tenable. This suggests that the underlying factors are correlated (the range of correlation coefficients was 2.88 to 3.69 ) due to the range of the activities are mostly gathering at casinos. With a sample size of 196 , and twelve variables for the Tourist Gaming Behavior Scale, this 1:16 ratio can be considered acceptable (Hinkin, 1995). For the result shown below, the Varimax orthogonal rotation to maximize variances of the factor loadings in a certain predetermined fashion was used (Hair, Black, Babin, Anderson, \& Tatham, 2010). This rotation produced a factor solution for all twelve items.

Table 2. Exploratory factor analysis of tourist gaming behaviors $(\mathrm{N}=196)$

\begin{tabular}{lll}
\hline Factors and Items & Factor loadings & Communalities \\
\hline Factor 1 (gambling behavior) & & .526 \\
I tend to gamble to earn money. & .701 & .642 \\
I tend to gamble. & .799 & .691 \\
I tend to take time when betting. & .754 & .735 \\
I tend to gamble in two or more casinos. & .765 & .658 \\
I tend to play table games. & & \\
Eigen-value =4.74, variance explained =24.64\%, Cronbach's $\alpha=.830$ & .788 & .687 \\
Factor 2 (entertainment behavior) & .858 & .784 \\
I tend to watch different kinds of shows in Macao. & .784 \\
I tend to watch ornamental shows in Macao. & & .645 \\
I tend to watch the show where I need to pay. & & \\
Eigen-value =1.72, variance explained =20.66\%, Cronbach's $\alpha=.823$ & .572 \\
Factor 3 (shopping behavior and F\&B behavior) & .795 \\
I tend to shop in casino outlets. & .635 \\
I tend to buy luxury goods. & .730 \\
I tend to have meals in casino. & & .658 \\
I tend to have meals in luxury restaurants. & & .547 \\
Eigen-value =1.24, variance explained =18.88\%, Cronbach's $\alpha=.751$ & .603 \\
\hline
\end{tabular}

As shown in Table 2, the resulting factor model explains 64.18 percent of the variance. The Kaiser's measure of sampling adequacy was .842 , matching the threshold value of meritorious (Tabachnick \& Fidel, 2001). Thus, we conclude that the relationships between pairs of variables are reliable. The result of Bartlett's test of sphericity was $933.297(\mathrm{df}=66, \mathrm{p}=.000)$, indicating that the factor structure has one or more factors. Communalities for each variable, indicating the amount of variance shared among variables (Hair et al., 2010), ranged from .572 to .858 , meaning that factors account for 57.2 to 85.2 percent of the variance in the variables. Even though an 
obvious cutoff rule for commonality is not determined, the values of. 45 or .5 could be a guideline to explain whether the variables meet acceptable levels of explanation (Hair et al., 2010; Tabachnick \& Fidell, 2001). In this study, all communalities were greater than .5 , and thus well accounted for by the factor solution.

The reliability alpha for all three factors are $.751, .823$, and .830 . The Factor 1 meets the criterion for acceptance, and Factor 2 and Factor 3 meet the good alpha reliability for an exploratory study proposed by Hair et al. (2010). In addition, Allen and Yen (2001) recommend a minimum of .60 in any case. Hence, we concluded that internal consistency for all three factors act well.

Factor loadings range from .572 and .853 of the three factors, which are obviously higher than the .45 criterion of Comrey and Lee (2013). We labeled the three factors as follows: (1) Gambling behavior, (2) Entertainment behavior, (3) Shopping and F\&B behavior, The mean scores in each factor ranged from 2.50 to 3.93, with standard deviations from 0.48 to 0.74 .

\subsection{Differences in Behavior of Gaming Tourist by Chinese and Non-Chinese}

Using the three factors as dependent variables, we conducted a multivariate analysis of variance (MANOVA) procedure to examine the effect of the two nationality groups as independent variables. The results showed that the nationality variable had a significant effect on the three behavioral factors $(\mathrm{p}<.001)$, allowing us to continue the analysis by undertaking General Linear Modeling (GLM) with repeated measures (Tabachnick \& Fidell, 2001).

The results of the GLM, which assessed the behavioral differences of the three subcultures, are shown in Table 3, with significant differences between the three groups in six of the seven factors $(p<.075$ or better). The exception was chips and money holding behavior $(p<.1)$. Considering the possibility that observations of behavioral differences could differ due to the employee respondents' personal characteristics such as age, education level, gender, and nationality, we attempted to analyze the GLM results to determine whether these employee characteristics work as covariates. Only in the case of factor 2 were employees' gender and education level as covariates significant at the .05 (See Table 3).

To assess the degree to which the independent variable(s) and dependent variable are related, we report the partial eta square for each factor, which measures the proportion of variance in the dependent variable that is associated with levels of an independent variable (Tabachnick \& Fidell, 2001). The higher the value, the stronger the association is between the dependent and independent variable. In addition, a series of Duncan's multiple range tests was used to identify the source of significant differences.

Table 3. Results of GLM to compare gaming tourist behavior by Chinese and non-Chinese

\begin{tabular}{|c|c|c|c|c|c|}
\hline & Two groups of $r$ & & & & \\
\hline Behavior & $\begin{array}{l}\text { Chinese tourist } \\
(\mathrm{N}=196)\end{array}$ & $\begin{array}{l}\text { None-Chinese } \\
\text { tourist } \\
(\mathrm{N}=196)\end{array}$ & $\begin{array}{l}\text { Within-subject } \\
\text { one-way ANOVA } \\
\text { F value }\end{array}$ & $P$ value & $\begin{array}{l}\text { Partial eta } \\
\text { square }\end{array}$ \\
\hline Factor 1 (gambling behavior) & 12.28 & 9.84 & 13.49 & .000 & .065 \\
\hline Factor 2 (entertainment behavior) & 9.73 & 8.36 & 9.33 & .003 & .046 \\
\hline Factor 3 (shopping and F\&B behavior) & 11.07 & 9.60 & 8.34 & .004 & .041 \\
\hline
\end{tabular}

\section{Discussion and Implications}

\subsection{Discussion and Managerial Implications}

This study was motivated by the need for research that can lead to a better understanding of the cultural differences and tourist behaviors in Macao. The concept of gaming used here is defined as that not only including gambling, but including entertainment, shopping, and Food \& beverage (F\&B), which activities relate to casinos of Macao. We discussed the represented behaviours among gamblers, entertainment, shopping, and F\&B which is followed by testing a structural model of the behaviors between Chinese and non-Chinese.

Firstly, we can get a conclusion that compares with non-Chinese, based on the means of the three underlying factors, Chinese is more tend to gamble and tend to gamble for money in Macao, this may relate to their history and culture. According to Raylu and Oei's (2004) research, it claims that culture is one of the factors that affects the gambling behaviors. Compare with other countries, Chinese are more frequent to gamble in the world. This 
finding match our conclusion and give an explanation for it. Further more, Chinese like to experience more than one casinos, this result supported by the previous studies what they show that most of the Chinese would like to visit three or more casinos during traveling in Macao (Chan, Wan, \& Wong, 2015). For the item of betting, Chinese and non-Chinese are familiar, both of them hold a moderate time when betting. This result is probably involved with the other characters such as motivation of gamble, education level, and the budget of chips.

Secondly, for the entertainment factor, Chinese tourists are easier than non-Chinese to choose Macao as a travel destination, they cost less time and transportation fee, and can easily adopt into the culture and language of Macao. For this, they may care more about their own habits, and tend to spend money for entertainment. Chinese like the ornamental shows more than non-Chinese. This can be explained that violent plays and bloody shows are strictly forbidden in mainland China. Chinese are more familiar with ornamental shows like girls dancing and other courtesy shows. Due to the long distance of traveling, non-Chinese prefer to explore fresh elements in Macao, and they are facing the risk of language and culture conflicts, what make them more carefully when consuming. An effective promotion of shows is needed.

Thirdly, on the shopping and F\&B factor, it is found that Chinese are more likely to choose the luxury goods and have meals in luxury restaurant and shop in casino outlets where the price is higher than non-casino places. This situation can show the desire of quality life of Chinese and also show the fast developing economy in China. Compare with Chinese tourists, non-Chinese may less care about the luxury, but the individuality, it can be explained by individualism-collectivism proposed by Hofstede (1984). The revenue of gambling is reducing now, how to keep economy develop stably is a problem. The Macao government decided to change the Macao to a leisure tourism destination. Reference the development of Hone Kong where is near by Macao, the luxury consuming can be considered to adopt by the local business.

The finding confirms the existence of gaming behavior variances between Chinese and non-Chinese, which the number of Chinese tourists has absolute advantage. We need to analyze the difference from power distance, uncertainty avoidance, individualism-collectivism, and masculinity-femininity (Minkov \& Hofstede, 2010). While all cultures have much in common, a wide situation of different behaviors can be found within each culture. The results of this study demonstrate that tourism marketers should take into account not only a tourist place of origin, but also their socioeconomic, educational, ideological, and political background (Wan et al., 2013). On the other hand, an insight of Chinese and non-Chinese differences will help casino and hospitality operators generally understand their customers' behavior, design efficient marketing strategies, and meet the needs of distinct cultural groups.

\subsection{Limitations and Future Research Directions}

First of all, the major limitation of this study is that part of the respondents did not take part in gambling, entertainment or shopping activities, but only came to Macao for historical heritages and to experience the street life and then eventually leave for Hong Kong. This kind of people occupied a certain part of the non-Chinese respondents and chose strongly disagree (1) to represent the meaning of didn't experience. With this limitation, the data will lead to bias for the result. Secondly, it depends on the tourist's self-report from memory. They had to remember specific behavior after experiencing a place in line with one of the three different factors, and then respond to the survey questions. As with any self-reporting survey, errors might occur in the recall process. Similarly, urbanization would be a key factors influence on tourism development (Zhang, Luo, Xiao, \&Denizci Guillet, 2013; Luo, Qiu, \& Lam, 2015; Luo, Qiu, Goh, \& Wang, 2015). Thirdly, this study measures gaming tourist behaviors based on a convenience sample in 196 copies. To further substantiate the findings, a future study could extend the sample of tourist and use a random sample. Lastly, this study focused on examining the behaviors between Chinese and non-Chinese. Future studies could assess the different Chinese cohorts and non-Chinese cohorts through self-evaluating surveys so that results can be more specific and accurate, also as a good way to make a comparison of this survey. Acquiring an understanding of the potential sources of customers will shed some light on how casino operators can better serve these markets. Future studies are required to explore and understand the range of subculture behaviors, and the managerial implications.

\section{References}

Allen, M. J., \& Yen, W. M. (2001). Introduction to measurement theory. Waveland Press.

Borgers, A., \& Timmermans, H. J. P. (2005). Modelling pedestrian behaviour in downtown shopping areas. In $10^{\text {th }}$ International Conference on Computers in Urban Planning and Urban Management, London, United Kingdom.

Chan, S. H. J., Wan, Y. K. P., \& Wong, I. K. A. (2015). Exploring the differences among Chinese casino 
gamblers' characteristics, motivations, and behaviors. Journal of Vacation Marketing, 21(1), 23-36. http://dx.doi.org/10.1177/1356766714542188

Comrey, A. L., \& Lee, H. B. (2013). A first course in factor analysis. Psychology Press.

Ellenbogen, S., Gupta, R., \& Derevensky, J. L. (2007). A cross-cultural study of gambling behaviour among adolescents. Journal of Gambling Studies, 23(1), 25-39. http://dx.doi.org/10.1007/s10899-006-9044-2

Hair, J. F., Black, W. C., Babin, B. J., Anderson, R. E., \& Tatham, R. L. (2010). Multivariate data analysis (7th ed.). Upper Saddle River: Pearson Education.

Hinkin, T. R. (1995). A review of scale development practices in the study of organizations. Journal of Management, 21(5), 967-988.

Hinkin, T. R. (1998). A brief tutorial on the development of measures for use in survey questionnaires. Organizational research methods, 1(1), 104-121. http://dx.doi.org/10.1177/109442819800100106

Hofstede, G. (1984). Culture's consequences: International differences in work-related values (Vol. 5). Sage.

Kemperman, A. D., Borgers, A. W., \& Timmermans, H. J. (2009). Tourist shopping behavior in a historic downtown area. Tourism management, 30(2), 208-218. http://dx.doi.org/10.1016/j.tourman.2008.06.002

Kim, S. S., Prideaux, B., \& Kim, S. H. (2002). A cross-cultural study on casino guests as perceived by casino employees. Tourism Management, 23(5), 511-520. http://dx.doi.org/10.1016/S0261-5177(02)00008-0

Lonner, W. J., Berry, J. W., \& Hofstede, G. H. (1980). Culture's Consequences: International Differences in Work-Related Values. University of Illinois at Urbana-Champaign's Academy for Entrepreneurial Leadership Historical Research Reference in Entrepreneurship.

Luo, J. M., Qiu, H., \& Lam, C. F. (2015). Urbanization Impacts on Regional Tourism Development: a Case Study in China. Current Issues in Tourism. http://dx.doi.org/10.1080/13683500.2015.1033385.

Luo, J. M., Qiu, H., Goh, C., \& Wang, D. (2015). An Analysis of Tourism Development in China from Urbanization Perspective. Journal of Quality Assurance in Hospitality and Tourism. http://dx.doi.org/10.1080/1528008X.2015.1016594.

Macao Statistics and Census Service. (2015). Statistics Database. Retrieved June 5, 2015, from http://www.dsec.gov.mo/TimeSeriesDatabase.aspx

McDonald, S., Thyne, M., \& McMorland, L. A. (2008). Means-end theory in tourism research. Annals of Tourism Research, 35(2), 596-599. http://dx.doi.org/10.1016/j.annals.2007.09.006

McIntosh, A. J., \& Thyne, M. A. (2005). Understanding tourist behavior using means-end chain theory. Annals of Tourism Research, 32(1), 259-262. http://dx.doi.org/10.1016/j.annals.2004.05.005

Mehrabian, A., \& Russell, J. A. (1974). The basic emotional impact of environments. Perceptual and motor skills, $38(1), 283-301$.

Minkov, M., \& Hofstede, G. (2010). Hofstede's fifth dimension: New evidence from the World Values Survey. Journal of Cross-Cultural Psychology, XX(X) 1-12.

Oei, T. P., Lin, J., \& Raylu, N. (2008). The relationship between gambling cognitions, psychological states, and gambling a cross-cultural study of Chinese and Caucasians in Australia. Journal of Cross-Cultural Psychology, 39(2), 147-161. http://dx.doi.org/10.1177/0022022107312587

Pearce, D. G., \& Butler, R. W. (1993). Tourism research: critiques and challenges. Routledge.

Pizam, A., \& Jeong, G. H. (1996). Cross-cultural tourist behavior: Perceptions of Korean tour-guides. Tourism Management, 17(4), 277-286.

Pizam, A., \& Sussmann, S. (1995). Does nationality affect tourist behavior? Annals of Tourism Research, 22(4), 901-917.

Raylu, N., \& Oei, T. P. (2004). Role of culture in gambling and problem gambling. Clinical psychology review, 23(8), 1087-1114.

Reisinger, Y., \& Turner, L. (1997). Cross-cultural differences in tourism: Indonesian tourists in Australia. Tourism Management, 18(3), 139-147.

Reisinger, Y., \& Turner, L. W. (2002a). Cultural differences between Asian tourist markets and Australian hosts, Part 1. Journal of travel Research, 40(3), 295-315. 
Reisinger, Y., \& Turner, L. W. (2002b). Cultural differences between Asian tourist markets and Australian hosts: Part 2. Journal of travel Research, 40(4), 385-395.

Schwarz, N. (2003). Self-reports in consumer research: The challenge of comparing cohorts and cultures. Journal of Consumer Research, 29(4), 588-594.

Sutton, W. A. (1967). Travel and understanding: Notes on the social structure of touring. International Journal of Comparative Sociology, September, 218-223. http://dx.doi.org/10.1177/002071526700800206

Tabachnick, B. G., \& Fidell, L. S. (2001). Using multivariate statistics (4th ed.). Boston: Allyn \& Bacon.

Tsang, N. K. F., \& Ap, J. (2007). Tourists' perceptions of relational quality service attributes: A cross-cultural study. Journal of Travel Research, 45(3), 355-363. http://dx.doi.org/10.1177/0047287506295911

Wan, P. Y. K. (2012). Increasing Chinese tourist gamblers in Macao: Crucial player characteristics to identify and exploit. UNLV Gaming Research \& Review Journal, 15(1), 4.

Wan, P. Y. K., Kim, S. S., \& Elliot, S. (2013). Behavioral Differences in Gaming Patterns among Chinese Subcultures as Perceived by Macao Casino Staff. Cornell Hospitality Quarterly, 54(4), 358-369. http://dx.doi.org/10.1177/1938965513485285

Wei, L., Crompton, J. L., \& Reid, L. M. (1989). Cultural conflicts: Experiences of US visitors to China. Tourism Management, 10(4), 322-332.

Yüksel, A. (2007). Tourist shopping habitat: Effects on emotions, shopping value and behaviours. Tourism management, 28(1), 58-69. http://dx.doi.org/10.1016/j.tourman.2005.07.017

Zhang, H., Luo, J. M., Xiao, Q., \& Denizci Guillet, B. (2013). The Impact of Urbanization on Hotel Development: Evidence from Guangdong Province in China. International Journal of Hospitality Management, 34, 92-98. http://dx.doi.org/10.1016/j.ijhm.2013.02.013

\section{Copyrights}

Copyright for this article is retained by the author(s), with first publication rights granted to the journal.

This is an open-access article distributed under the terms and conditions of the Creative Commons Attribution license (http://creativecommons.org/licenses/by/3.0/). 